\title{
Correction to: TEM Study of the Radular Teeth of the Chiton Acanthopleura japonica
}

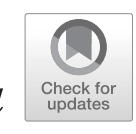

\author{
Mitsuo Kakei, Masayoshi Yoshikawa, and Hiroyuki Mishima
}

\section{Correction to:}

Chapter 2 in: K. Endo et al. (eds.), Biomineralization, https://doi.org/10.1007/978-981-13-1002-7_2

In the original version of chapter 2 , references 5 and 12 were incorrect. In this version, references 5 and 12 are corrected. The corrected references have now been added in the Chapter which reads as follows:

\section{Reference 5}

Weaver JC, Wang Q, Miserez A, Tantuccio A, Stromberg R, Bozhilov KN, Maxwell P, Nay R, Heier ST, DiMasi E, Kisailus D (2010) Analysis of an ultra hard magnetic biomineral in chiton radular teeth. Materialstoday 13 (1-2):42-52

\section{Reference 12}

Nemoto M, Wang Q, Li D, Pan S, Matsunaga T, Kisailus D (2012) Proteomic analysis from the mineralized radular teeth of the giant Pacific chiton, Cryptochiton stelleri (Mollusca). Proteomics 12:2890-2894 